\begin{tabular}{|c|c|c|}
\hline $\begin{array}{l}\text { PKS } \\
\text { PUBLLC } \\
\text { KNOWEDGE } \\
\text { PROJECT }\end{array}$ & $\begin{array}{c}\text { REVISTA DE GEOGRAFIA } \\
\text { (RECIFE) } \\
\text { http://ww.revista.ufpe.br/revistageografia }\end{array}$ & 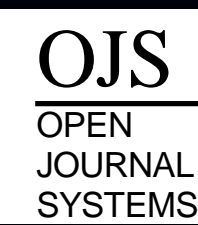 \\
\hline
\end{tabular}

\title{
DAS ÁGUAS QUE CONVERGEM AS ÁGUAS QUE DIVERGEM: MERCADORIZAÇÃO DA ÁGUA NA REGIÃO DO CARIRI CEARENSE ${ }^{1}$
}

\author{
Francisco Wlirian Nobre ${ }^{1}$ \\ ${ }^{I}$ Mestre em Geografia pela Universidade Federal do Cariri.Email: lironobre@yahoo.com.br
}

Artigo recebido em 16/06/2017 e aceito em 18/09/2017

\begin{abstract}
RESUMO
Considerada por muitos como um oásis no meio do sertão, a região do Cariri representa uma das áreas com maior riqueza hídrica do estado do Ceará. Para os índios Kariris, primeiros habitantes da região, a relação com a água estava ligada as suas próprias condições de existência, mas com a chegada dos colonizadores, no século XVIII, a mercadorização da água foi induzida produzindo uma nova geografia das águas imbuída pelas forças políticas e econômicas que se estabeleceram na região. Objetiva-se nessa pesquisa, através de uma metodologia de análise documental e revisão da literatura, demonstrar um debate teórico sobre o processo de mercadorização da água na região do Cariri cearense. Observamos que a transição das formas de produção do espaço intensificadas com o avanço das políticas neoliberais acentuaram os problemas de degradação e injustiça ambiental representando um sentido de natureza com significado oposto a concepção de mundo dos índios Kariris.
\end{abstract}

Palavras-chave: Água; mercadorização; comunidade; território.

\section{OF THE WATERS GET TOGETHER THE WATER THAT DISAGREE: WATER MERCHANDISING IN THE REGION OF CARIRI CEARENSE}

\begin{abstract}
Considered by many as an oasis in the middle of the hinterland, the Cariri region represents one of the most water rich areas of the state of Ceará. For the Kariris Indians, the first popularion of the region, the relationship with water was linked to their own conditions of existence, but with the arrival of colonizers in the XVIII century, the commodification of water was induced by producing a new geography of waters imbued by political forces and economic ones that have settled in the region. The objective of this research, through a methodology of documentary analysis and literature, review, is to demonstrate a theoretical debate about the process of water merchanization in the Cariri region of Ceará. We note that the transition from intensified forms of space production to the advancement of neoliberal policies has accentuated the problems of environmental degradation and injustice by representing a sense of nature with opposite meaning to the worldview of the Kariris indians.

Key-words: Water; Goods; community; territory.
\end{abstract}

\footnotetext{
${ }^{1}$ As ideias contidas nesse artigo foram extraídas a partir da dissertação, "Os efeitos do Cinturão das Águas do Ceará - CAC no distrito de Baixio das Palmeiras, Crato - CE", defendida no início de 2017 pelo Programa de Desenvolvimento Regional Sustentável - PRODER da Universidade Federal do Cariri - UFCA. 


\section{Introdução}

Desde a Revolução Industrial as sociedades modernas vêm aumentando a demanda por água para diversos fins potencializados pelo uso da energia e pelo avanço nas técnicas de captação, armazenamento e distribuição. Durante o século XX praticamente chegamos ao limite no domínio e controle da água e simultaneamente atingimos uma perspectiva sombria em relação ao futuro da água no planeta. Com a chamada crise ambiental passamos do debate de bem abundante e infinito para uma perspectiva finita e escassa consolidando a questão como um dos maiores desafios da contemporaneidade.

Apesar do cenário preocupante o consumo por água vem crescendo a cada ano. A UNESCO em relatório publicado em 2012 alertou que o volume de água subterrânea tenha triplicado nos últimos 50 anos levando a exaustão de muitos aquíferos. Com a intensificação das mudanças climáticas provocadas pelo aquecimento global essa projeção pode aumentar nos próximos anos. As técnicas de extração, armazenamento e distribuição de água avançaram consideravelmente e continuam fazendo progressos captando o bem em locais antes inacessíveis.

Diante desse consenso governos de todo o mundo têm direcionado ações de governança no sentido de atingir uma gestão de água eficiente com disponibilidade em seus múltiplos usos. A discussão tem se acirrado devido a irregularidade geográfica na disponibilidade da água nos países e nas regiões bem como o seu desigual acesso e suas diferentes formas de utilização e consumo.

Entre as soluções para amenizar os problemas em torno da questão hídrica os países desenvolvidos e os organismos multilaterais apresentaram a proposta de atribuição de um valor econômico para a água. A partir daí a lógica neoliberal predominou na formulação das políticas públicas principalmente nos países em desenvolvimento.

À medida que a preocupação com a água foi ganhando pauta na agenda política a sua mercadorização foi se acentuando sob a garantia de que a submissão à lógica do mercado atuaria de modo eficiente na gestão. No Brasil esse discurso foi fundamental para que os serviços de água como abastecimento humano e saneamento fossem transferidos a iniciativa privada. Nesse processo vem crescendo também o controle e domínio dos territórios abundantes em água através de ações estruturais nos corpos hídricos.

É a partir dessas premissas que pretendemos refletir sobre o processo de mercadorização da água na região do Cariri cearense. Utilizando uma metodologia de análise 
documental e revisão da literatura procuramos demonstrar como o debate teórico sobre o processo de mercadorização da água vem sendo colocado nesse espaço.

A região do Cariri cearense localizada ao sul do estado do Ceará está situada na Bacia Sedimentar do Araripe englobando territórios dos estados de Pernambuco, Ceará e Piauí no alto sertão nordestino, cobrindo uma área com cerca de $11.000 \mathrm{~km}^{2}$, sendo delimitada, aproximadamente, pelas coordenadas geográficas: $38^{\circ} 30^{\prime} 00$ e $40^{\circ} 55^{\prime} 00$ de longitude oeste de Greenwich; $7^{\circ} 10^{\prime} 00^{\prime \prime}$ a 7 $7^{\circ} 50^{\prime} 00$ de latitude sul. Essa formação geológica se constitui um importante divisor de águas das bacias hidrográficas dos rios São Francisco ao sul, Jaguaribe ao norte e Parnaíba a oeste (DNPM, 1996).

Nesse pacote sedimentar a Chapada do Araripe se destaca na paisagem. Formado por um platô com altitudes que podem variar entre 750 e 970 metros cobrindo uma superfície de aproximadamente $180 \mathrm{~km}$ de comprimento no sentido leste-oeste com uma largura que pode variar entre 30 e $80 \mathrm{~km}$ (MENEZES, 2007).

Por causa da chapada a região possui índice pluviométrico superior a $1.000 \mathrm{~mm}$ sendo considerada uma das áreas que mais chove no estado do Ceará. Os aquíferos da região, em especial o aquífero Missão Velha, representam a maior e mais importante bacia hidrogeológica do estado do Ceará.

Foi nesse território, com boas condições edafoclimáticas, que por volta do século IX os índios Kariris chegaram. Os Kariris constituíam um grupo numeroso e habitavam as áreas mais férteis com água em abundância e viviam em disputa com outros grupos indígenas para defenderem seu território. A água e a terra não eram apropriadas por eles para fins privados ou de caráter pecuniário. Dela eles retiravam apenas o suficiente para a sobrevivência do grupo que decorria da agricultura de subsistência, da pesca, da coleta e da caça.

Mas no século XVIII o modo de vida dos indígenas foi drasticamente alterado com a chegada do invasor. No contexto histórico da época os países europeus impunham um processo de expansão marítimo comercial ao Brasil que tinha como objetivo fornecer recursos naturais para o crescente atendimento ao mercado capitalista.

Os colonizadores com ajuda da igreja e depois os descendentes de famílias tradicionais oriundas principalmente da Bahia e do Pernambuco foram se apropriando das principais fontes de água da encosta da Chapada do Araripe alterando profundamente o regime hídrico. Cultivando cana-de-açúcar no vale e depois na encosta e criando gado bovino solto no topo da chapada se estabeleceu um intenso conflito com os Kariris desencadeando em massacres, escravização, submissão e expulsão dos grupos que viviam há nove séculos nesse território. 
Ainda hoje os descendentes dessas famílias tradicionais, herdeiras dos primeiros sesmeiros, controlam e dominam as águas e as terras da encosta da Chapada do Araripe. Essa situação de uso desigual ao acesso à água se agravou quando a chamada nova e moderna legislação hídrica garantiu o direito de uso para essas famílias sob o discurso de que eles são realmente os donos da água.

Com o alerta da escassez hídrica sendo brandido em escala global os territórios abundantes em água se tornaram objeto de disputa entre proprietários e empresas capitalistas. Empresários do setor de turismo e do setor imobiliário entraram na disputa do território antes controlado pelos produtores de cana-de-açúcar. Os equipamentos urbanos de luxo como os balneários, as chácaras e as casas de veraneio estimularam a indústria do turismo e do lazer no Cariri tornando esses lugares em ambiente de consumo para as classes mais abastadas.

Em 2009 o Governo do Estado do Ceará criou a Região Metropolitana do Cariri RMC. Depois disso investimentos em obras de grande envergadura além da chegada de grandes empresas produziram um dinâmico crescimento econômico que vem provocando maior pressão aos recursos naturais da região. Diversos pesquisadores e movimentos sociais expõem preocupações com o aumento da demanda hídrica (NOBRE, 2017).

Com investimentos produtivos nacionais e internacionais várias indústrias foram atraídas por subsídios fiscais oferecidos pelos municípios caririenses e muitas delas impactaram diretamente nas áreas de conservação da chapada como a Área de Proteção Ambiental - APA Chapada do Araripe.

Além da injustiça ambiental e da segregação espacial provocada pelo contexto histórico os processos atuais de desenvolvimento têm provocado graves problemas na reposição dos aquíferos. O crescimento da malha urbana no vale provoca impermeabilização do solo dificultando a infiltração da água. A expansão de balneários, condomínios fechados e loteamentos na encosta da chapada acentua a retirada da floresta que é fundamental para o ciclo hidrológico.

Constatamos, portanto, que apesar da visível apropriação privada, da destruição e da injustiça ambiental as ações são legalizadas pelas instituições que deveriam minimamente proteger e promover justiça ao acesso dos recursos hídricos. Enquanto a população do Cariri começa a ter sérios problemas em relação aos serviços de abastecimento e saneamento, como ficou evidente nesses anos de seca, uma pequena elite local e em alguns casos empresas de fora tem garantia de lucros com a apropriação privada da água. 


\section{As águas que convergem}

No Cariri cearense a Chapada do Araripe se destaca na paisagem pela sua beleza cênica e pela importância na dinâmica edafoclimática da região. Essa forma de relevo, inserida na Bacia Sedimentar do Araripe, conforme mostra a figura 1, é considerada um "caminho das águas" devido a sua formação constituída por um enorme platô onde se encontra as nascentes de três importantes unidades hidrológicas do nordeste: a Bacia do Riacho da Brígida, ao sul, no estado de Pernambuco que se integra a Bacia do Rio São Francisco; o alto Jaguaribe, ao norte, no Ceará com seus componentes Sub-bacia do Cariús e Sub-bacia do Salgado a oeste e leste; e a Sub-bacia do Rio Canindé, afluente do Rio Parnaíba, a oeste, no estado do Piauí (LIMAVERDE, 2013).

Figura 1 - Localização da Bacia Sedimentar do Araripe

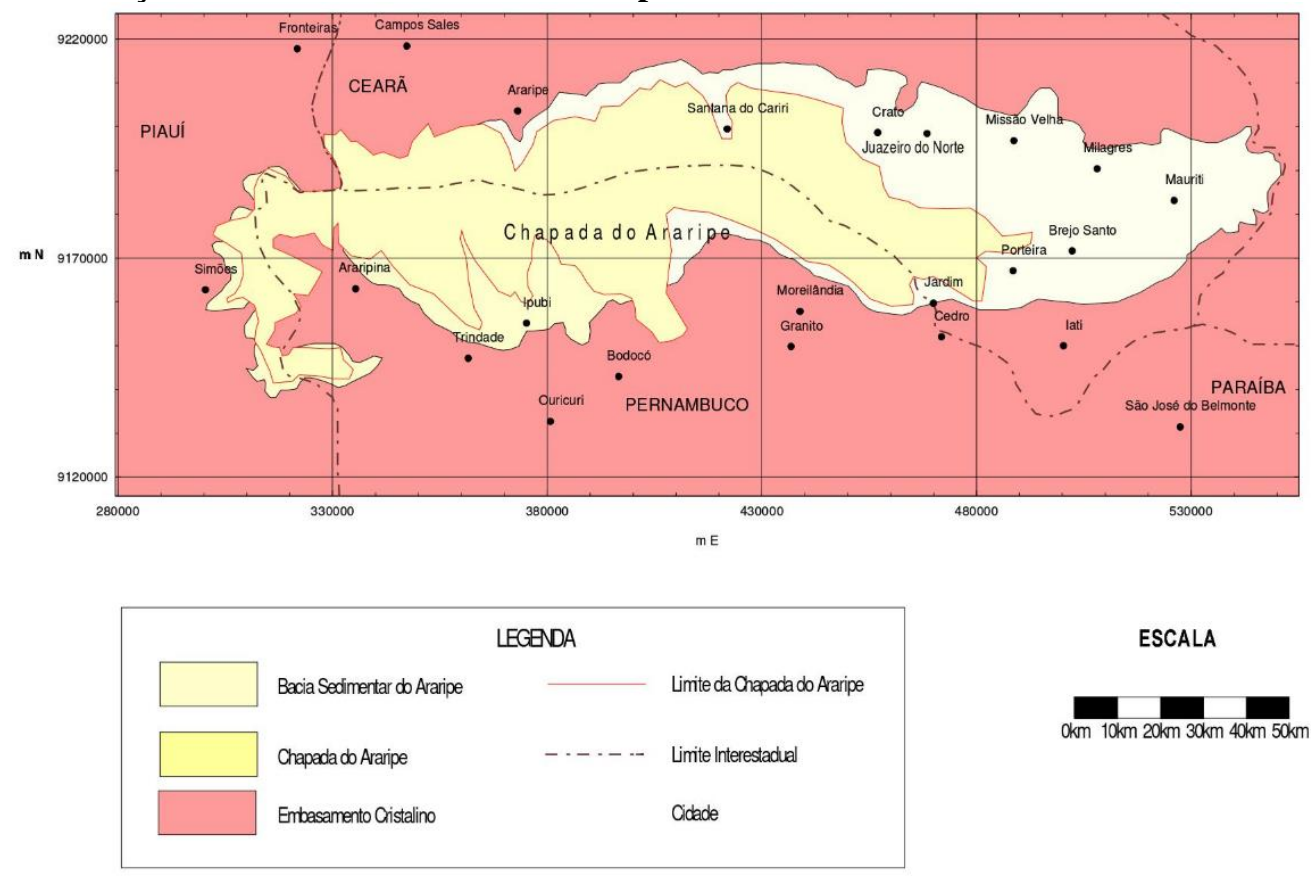

Fonte: DNPM (1996).

No topo da chapada o solo poroso e a vegetação florestal úmida favorece a infiltração da água da chuva constituindo um complexo sistema de aquíferos. Na encosta da chapada, entre 620 e 780 metros jorram 344 fontes de água, sendo 293 fontes na porção cearense, 43 no lado pernambucano e oito no Piauí (BRITO, 2016).

Essas fontes originam inúmeros rios e riachos que formam a bacia do rio Salgado drenando uma área total de $12.865 \mathrm{~km}^{2}$ representando 8,25\% do território cearense abrangendo 23 municípios (SABOIA, 2015). Entre os maiores municípios da região destaca- 
se o núcleo urbano formado pelas três principais cidades; Crato, Juazeiro do Norte e Barbalha. Nesse núcleo urbano conhecido como Crajubar estima-se que $90 \%$ do total de abastecimento público de água ocorre por meio de poços profundos ou fontes naturais (CEARÁ, 2008).

Foi nesse território que viveu uma das tribos indígenas mais sofisticadas do Nordeste brasileiro. As tribos que viveram no Cariri faziam parte do grupo linguístico Kariri ${ }^{2}$ Sua origem está relacionada a classe dos Tapuias, índios de língua travada, que constituíam um grupo das tribos que não falavam a língua tupi e viviam em conflitos com esses.

Limaverde (2013) supõe que os povos da nação Kariri migraram para a região no século IX ocupando as nascentes dos principais rios e riachos. Pompeu Sobrinho (1950) tomando como referência pesquisas de vários cronistas, naturalistas e historiadores afirma que eles podem ter migrado da região Norte do Brasil e seguindo o curso de rios caudalosos chegaram ao Nordeste.

Já no Nordeste, Studart (2011), explica que eram os senhores da orla marinha e foram se espalhando pelo sertão por causa dos conflitos com os colonizadores. Figueiredo Filho (2010, p.7) acrescenta que ao chegarem no rio São Francisco os indígenas migraram para o Cariri. "O seu caminho foi o do Riacho da Brígida e do Pageú, o mesmo que, em parte, seria utilizado pelos povoadores brancos, após a descoberta".

Irineu Pinheiro (2010, p.8) explica porque a região do Cariri foi escolhida pelos índios:

É o Cariri uma estreita faixa de terreno sertanejo, com fontes que nunca secam. Veiu-lhe o nome de seus habitantes primitivos, os índios cariris, originários de "lago encantado", conforme êles diziam, talvez o rio das Amazonas, no pensar de Capistrano de Abreu. Na sua larga peregrinação, viajaram, a princípio ao longo do litoral, mas expulsos da beiramar pelos tupininquins e tupinambás, portadores de língua geral, internaram-se nos sertões, onde também há "pousos felizes, vales fartos e frescos".

Entre os historiadores tradicionais não está claro ainda a etimologia do vocábulo Cariri, Kariri ou Kiriri. Irineu Pinheiro (2010) considera uma das etimologias com a origem em caa mato e ira mel, ou cai queimado, ira mel ou riré depois que. Figueiredo Filho (2010) avalia que a palavra significa tristonho, calado, silencioso ${ }^{3}$, por sua vez, Pompeu Sobrinho

\footnotetext{
${ }^{2}$ Entre os estudiosos há dúvidas se todos os grupos que habitavam a região pertenciam ao tronco linguístico Kariri.

${ }^{3}$ Se por um lado essa característica já o diferenciava de outras tribos guerreiras que habitavam o Nordeste essa ideia é controversa, visto que, há relatos de que os Kariris empreenderam uma forte resistência ao invasor na Nobre, 2017 ISSN 0104-5490 206
} 
(1950) explica que o nome Kariri se origina da palavra indígena Kari que significa água daqui.

A água abundante da região sempre teve uma relação direta com a existência dos Kariris. Pesquisas arqueológicas tem demonstrado que os sepultamentos indígenas ocorriam em áreas ribeirinhas (LIMAVERDE, 2013). Na tradição oral os mitos e lendas ${ }^{4}$ que atravessaram gerações e ainda hoje permeia o imaginário do caririense comprova a forte ligação do indígena com a água.

A lenda da Lagoa Encantada que era a morada da Mãe D’Água, grande serpente com metade do corpo formado por uma mulher, é um exemplo de como os índios se relacionavam com a água. Insatisfeita com a chegada dos colonizadores a Mãe D’Água ameaçava retirar a grande pedra que está posicionada na fonte da Batateira (maior fonte da região). Os Kariris acreditavam que todo o vale caririense era um grande mar subterrâneo e onde hoje é a Igreja Matriz de Crato $^{5}$ havia uma Iara. A retirada da Pedra da Batateira significaria uma inundação em todo o vale de onde ninguém conseguiria escapar. O Padre Antônio Gomes de Araújo, importante estudioso da história do Cariri, explica o mito da inundação.

Nossos índios tinham a sua Jara, jovem de cabelos verdes, senhora dos rios e das fontes, e que, às vezes se dava ao luxo de atrair os remeiros às corredeiras. O mito achou guarida no espírito do povo rude. Na Missão do Miranda, os índios localizavam a morada da Iara - Mãe D’Água, para o vulgo - num lago subterrâneo correspondente ao altar de N. S. da Penha. Acompanhavam a lenda com outras: um dia a Iara subverteria a povoação submergindo-a no lago. Os brancos simplórios herdaram a lenda-mito [...] Descontente com a invasão dos brancos, a Iara resolvera destruir a povoação do Miranda, retirando a pedra que controlaria o escape das águas da nascente Batateira (ARAÚJO, 1971, p.104).

Outra versão lendária explica que os índios vencidos, em lutas anteriores, havia "encantado" (tampado) a grande nascente da Chapada do Araripe com a pedra da Batateira. Nas águas acumuladas no subsolo vivia uma serpente sagrada que faria deslocar a pedra e

tentativa de defender seu território. Studart (2011) afirma que entre as tribos que disputavam o território da região estavam os Calabaças e os Cariús.

${ }^{4}$ No Memorial do Homem do Cariri (Fundação Casa Grande), localizado no município de Nova Olinda, estão preservados os vestígios materiais do homem pré-histórico da Chapada do Araripe. Também está organizado o patrimônio imaterial desses povos de onde se pode constatar a sua relação com água.

${ }^{5}$ Onde hoje é a Praça da Igreja matriz do Crato havia uma das maiores aldeias indígenas do Cariri. A missão religiosa liderada pelo frade capuchinho Carlos Maria de Ferrara foi chamada de missão do Miranda. 
todo o vale do Cariri seria inundado. Os índios Kariris voltariam a ser uma nação livre, senhores do mar, viveriam na paz e tranquilidade de um paraíso (CARIRI, 2016).

O modo de vida dos indígenas caririenses começa a ser irreversivelmente afetado no século XVIII quando os colonizadores europeus e seus descendentes vindos principalmente das províncias de Pernambuco e Bahia foram atraídos pelas terras férteis e pela riqueza hídrica da região. Desqualificar os saberes desses povos foi uma das estratégias de dominação imposta pelos colonizadores. Os Kariris, vistos pelos colonizadores como primitivos e atrasados foram desterritorializados e as águas das fontes utilizadas como parte da estrutura de poder do colonizador.

Assim, um novo processo de produção espacial foi desencadeado na região com ações exploratórias que promoveram a destruição sistemática dos territórios e das territorialidades dos índios Kariris. Com o estabelecimento dos colonizadores e a formação de uma elite regional a propriedade privada da água e os usos desiguais foram instituídos atacando sempre que necessário a ancestralidade indígena e toda sua forma de se relacionar com a água.

\section{As águas que divergem}

No século XIX as famílias tradicionais do Cariri já tinham se apropriado das principais fontes de água alterando profundamente o regime hídrico desviando o curso dos principais rios para o cultivo de cana-de-açúcar. Para Brito (2016) essas famílias que se julgavam donas da água começaram a disputar as principais fontes da encosta e vários conflitos foram desencadeados.

Com o objetivo de solucionar os conflitos o presidente da Província do Ceará, a pedido de uma das famílias mais tradicionais do Cariri, os Gomes de Matos, elaborou uma Resolução Provincial ( $n^{\circ}$ 645) em 17 de janeiro de 1854. Brito (2016) citando Gonçalves (2001) explica que o Decreto, regulamentado em 1856, pela Câmara do Crato, estabeleceu o direito de uso e comercialização a partir do sistema de telha d'água ${ }^{6}$. A negociação era feita em cartório e permitia que o interessado escolhesse as horas ou os dias de telhas d'água na sua propriedade. A Figura 2 representa um esquema do sistema de telhas d'água de uma das principais fontes da Chapada do Araripe, a fonte da Batateiras, localizada na cidade de Crato.

\footnotetext{
6 A telha d’água era uma medida de vazão utilizada em Portugal. Cada telha media aproximadamente 20 polegadas de circunferência e equivalia em média 64.800 litros/hora.

Nobre, 2017 ISSN 0104-5490 
Figura 2 - Esquema de telhas d'água da fonte da batateiras

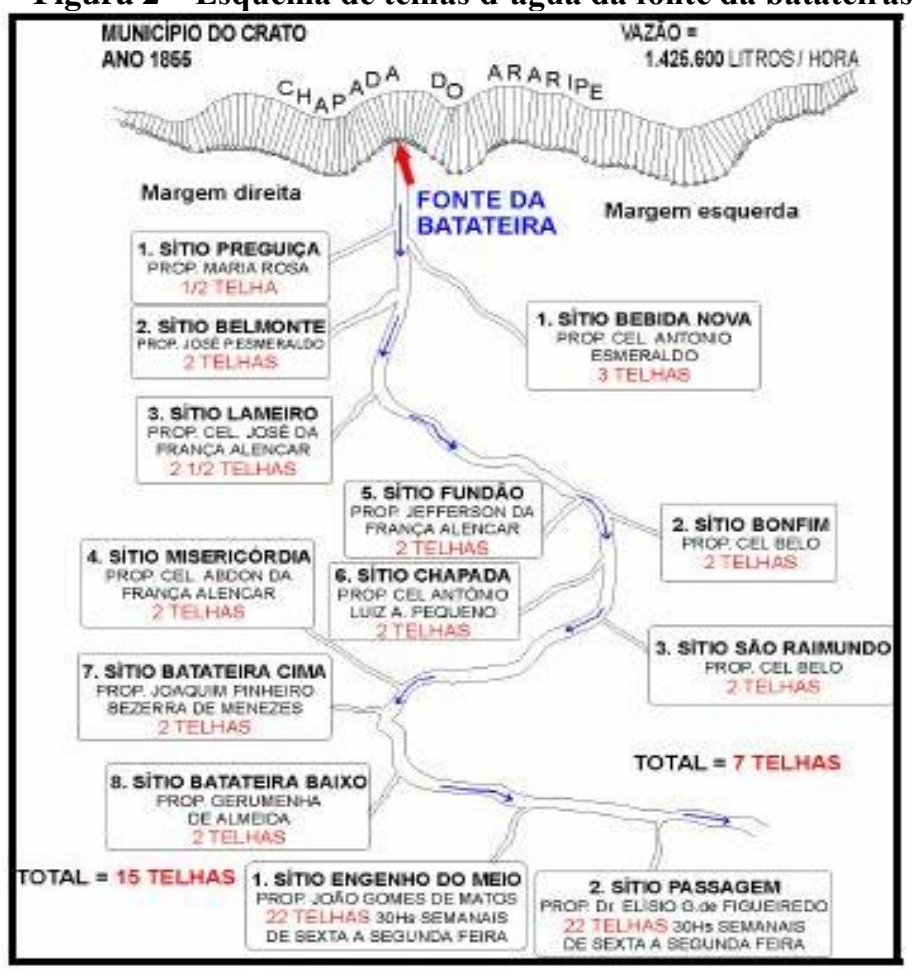

Fonte: Gonçalves (2001) apud Brito (2016).

Os donos das terras adquiridas nas políticas de concessão das sesmarias passaram a utilizar o sistema de telhas d'água como forma de controle das águas que ressurgiam na encosta da Chapada do Araripe. A perpetuação da dominação e do poder dessa elite agrária era legalizado na:

[...] medida em que os proprietários foram aos cartórios, muitas vezes criados por seus familiares, e, registraram-se como donos das águas. Essa concentração e esse controle de uso e fluxo da água, tendo em alguns pontos, inclusive, vigia do curso da água, exclui do uso populações tradicionais que vivem nas encostas da chapada, demonstrando outro caráter intrínseco desse processo de apropriação das terras/água: o conflito (BRITO, 2016, p.147).

Já no século XX o impacto ambiental na encosta da chapada provocado pela produção de cana-de-açúcar havia reduzido consideravelmente a vazão das fontes. A ocupação urbana principalmente nas cidades de Crato e Barbalha e a criação de balneários contribuiu para redução do fluxo das fontes. 
Na última década do século XX a força do capital se instalou na encosta da Chapada do Araripe com condomínios fechados, ambientes luxuosos de lazer e até mesmo com empresas que se apropriaram dos recursos oferecidos pela chapada como a madeira, os minérios e a própria água. A geopolítica mundial experimentava o modelo neoliberal e a mercadorização da água se tornou um dos elementos centrais para as políticas neoliberais operadas por grandes empresas e organismos multilaterais chanceladas pelos governos em especial nos países em desenvolvimento como o Brasil.

Com a institucionalização das políticas de gestão de recursos hídricos a água foi vista cada vez mais como insumo sujeito as leis do mercado e como contraponto a essa visão houve poucos avanços na legislação ambiental. No Cariri a criação da Área de Proteção Ambiental APA Chapada do Araripe ${ }^{7}$, em 1997, teve como objetivo específico para a questão hídrica tentar conservar os leitos naturais das águas pluviais e das reservas hídricas da encosta.

Embora a criação das APAs objetivem a restrição e proibição de algumas atividades não é exatamente o que ocorre. Brito (2016), em sua pesquisa, constatou que a legitimidade dos decretos elaborados pelo Estado bem como a eficiência na execução e fiscalização dos atos normativos são colocados em questão frente a expansão das atividades econômico-financeiras dentro da APA Araripe.

Em Barbalha uma empresa produtora de cimento, chamada Ibacipe, teve parte de sua infraestrutura construída dentro da área da APA Chapada do Araripe e retira a matéria-prima (calcário laminado) no município de Nova Olinda. Situação semelhante é a indústria de calçados Grendene que também se encontra dentro da área da APA Chapada do Araripe, no município de Crato. Para a construção da Grendene uma extensa área florestal foi desmatada e os rios que passam pela proximidade da indústria, como o rio Granjeiro é utilizado para despejo dos dejetos industriais (BRITO, 2016).

Principalmente nas cidades de Crato e Barbalha o turismo balneário se apropriou das maiores fontes do Cariri transformando-as em objeto de consumo com ambientes aprazíveis e paisagens pitorescas.

A indústria do turismo e especialmente do lazer, aqui no Cariri, transforma em mercadoria o ar, o sol, a água das fontes, a beleza da paisagem que são vendidos nos clubes e balneários em resposta à

\footnotetext{
${ }^{7}$ A APA Chapada do Araripe prevê uma legislação que atenda uma área com cota acima de 500 metros de altitude, ou seja, na prática as fontes que estão entre 600 e 750 metros estariam em tese protegidas.

Nobre, 2017

ISSN 0104-5490 210
} 
necessidade de fuga do forte calor presente nos centros urbanos da região (MENEZES, 2007, P.355).

Em Crato são pelo menos quatro grandes clubes recreativos privados: Granjeiro, Serrano, Itaytera e Bec, apenas o balneário Nascente é público. Em Barbalha destaca-se dois balneários particulares, o Arajara Park e o Caminho das Águas. Já o balneário Caldas, também na cidade de Barbalha, conta com uma Parceria Pública Privada, facilitando o acesso das classes menos favorecidas que em muitos casos ficam restritas a pequenas trilhas e fontes menores espalhadas em toda a encosta da Chapada do Araripe.

Desde o ano de 2009 com a criação da Região Metropolitana do Cariri - RMC o Governo do Estado vem impulsionando o desenvolvimento econômico da região através de obras de infraestrutura e investimentos em diversos setores. A RMC foi instituída a partir do núcleo conurbado formado pelos municípios de Crato, Juazeiro do Norte e Barbalha que passou a ser chamado de Crajubar. Completam a $\mathrm{RMC}^{8}$ os municípios vizinhos ao Crajubar: Farias Brito, Nova Olinda, Santana do Cariri, Jardim, Missão Velha e Caririaçu.

O atual estágio da dinâmica urbana concentrada no triângulo Crajubar acentua a demanda e a consequente mercadorização da água na região. Juazeiro do Norte, que representa um dos mais importantes polos calçadistas do Brasil, figura como uma das cidades que mais cresce no Ceará apresentando um dos comércios mais pujantes do Nordeste. Grandes redes de supermercados ${ }^{9}$, com investimentos de capital internacional, já estão instaladas na cidade comercializando no varejo e no atacado.

Setores estratégicos como o controle de fontes hídricas, a produção e comercialização de água mineral engarrafada e bebidas gaseificadas cresce na região. As marcas Cambará, São Geraldo, Castelo, Cristalina dos Alpes e Serra Bela possuem fontes próprias no Cariri e disputam os mercados da região. A cambará ousou ao criar uma garrafa de $500 \mathrm{ml}$ com o formato de Padre Cícero para estimular as vendas nos períodos das romarias para Juazeiro do Norte $^{10}$. A empresa cearense Indaía possui uma distribuidora em Crato, é a maior indústria de água mineral do país controlando mais de $30 \%$ do mercado nacional presente em todas as regiões com mais de 40 fontes no Brasil.

\footnotetext{
${ }^{8}$ De acordo com o IBGE (2010) a RMC conta com 564.478 habitantes.

${ }^{9}$ Entre as principais redes de supermercados estão o Walmart, Hiper Bompreço, São Luiz, Assaí e Atacadão.

${ }^{10} \mathrm{O}$ pujante comércio de Juazeiro do Norte se aquece a cada nova romaria com a comercialização de artigos relacionados a religiosidade. A cidade já figura como um dos maiores centros de romarias do Brasil. 
O crescimento no setor de água mineral no Cariri evidencia a força reguladora do mercado que tanto transforma abundância em escassez como cria cenários de degradação. Isso é usado, obviamente, como publicidade para atender os interesses do capital. A mesma água que poderia atender as demandas da população passa a ser comercializada por empresas capitalistas. Esse discurso da escassez hídrica no Cariri, parte fundamental das estruturas de poder, ficou mais evidente com a chegada de uma grande obra hídrica, o Cinturão das Águas do Ceará - CAC.

O CAC propõe transpor as águas para as bacias hidrográficas do Ceará a partir do Eixo Norte da Transposição do Rio São Francisco. O projeto foi elaborado pelo Governo do Estado e tem como órgão empreendedor a Secretaria de Recursos Hídricos - SRH. As águas do CAC partirão da barragem Jati e percorrerão 149, $82 \mathrm{~km}$ com vazão estimada em $30 \mathrm{~m}^{3} / \mathrm{s}$ cortando oito municípios do Cariri. Esse percurso inicial representa o Trecho 1 da obra ${ }^{11}$ que teve início em 2013, com previsão de 36 meses, e ainda não foi concluído tendo adiado sistematicamente os prazos de entrega.

De acordo com o EIA/RIMA (2010) do projeto, duas cidades do Cariri serão impactadas em suas áreas de APAs, Crato e Barbalha. O canal principal ocupará uma faixa de domínio com largura de 100 metros para cada lado, mas a Área Diretamente Afeteda - ADA pelo empreendimento atingirá uma área equivalente a $2 \mathrm{~km}$ para cada lado dependendo da declividade do relevo. Estima-se que no Trecho 1 seja desmatada uma área equivalente a 2.996 hectares, onde 54,0\% deste total apresenta uma cobertura vegetal preservada. Considerando a declividade do relevo em grande parte do traçado essa margem será aumentada.

Mas, enquanto a destruição desencadeada pelo CAC é ofuscada, os seus benefícios são propagandeados excessivamente como necessário para acompanhar o dinamismo econômico da região. O EIA/RIMA (2010) justifica que a água existente na região não será suficiente para suprir o crescimento econômico e a previsão é que além dos nove municípios interceptados pelo sistema adutor os benefícios se estenderão aos municípios de Milagres, Farias Brito, Lavras da Mangabeira, Iguatu, Icó, Orós, Mauriti, Aurora, Cariús e Quixelô. A previsão é que a população atendida num horizonte para 2040 seja na ordem de 530.938 habitantes.

${ }^{11}$ O CAC é considerado a maior obra hídrica do Ceará, serão construídos, aproximadamente, 1.252,65km de canais, túneis e sifões divididos em três trechos e cinco ramais fazendo a integração de todas as onze bacias hidrográficas do estado. Apenas o Trecho 1 está em execução interceptando os municípios de Jati, Porteiras, Abaiara, Brejo Santo, Missão Velha, Barbalha, Crato e Nova Olinda.

Nobre, $2017 \quad$ ISSN 0104-5490 
Novos conflitos territoriais pelo acesso a água são engendrados a partir das novas condições ambientais provocados pelo processo de urbanização e aumento da demanda. A violência praticada ao povo Kariri e seus descendentes espalhadas em inúmeras comunidades tradicionais da encosta da chapada é semelhante à agressão praticada as fontes hídricas.

As ações realizadas pelos colonizadores e seus descendentes e agora pelas empresas, com aval do Estado, operam como indutor no processo de expansão do capital no Cariri privatizando a água e contribuindo para um desenfreado processo de degradação.

Esse contexto político-econômico deve ser interpretado de forma mais abrangente como inserção da mercadorização e privatização da água no contexto de crise do capitalismo. Mitidiero Junior (2016) apresenta uma reflexão teórica em que as transformações espaciais objetivam promover o trancafiamento da água, e de outros elementos da natureza, tendo em vista o aprofundamento da crise da economia global. Para o autor a ampliação de investimentos de capital nos territórios com abundância em recursos naturais, como a água, é resultado da crise de reprodução ampliada do capital. Diferente das crises anteriores, consideradas cíclicas, agora a crise é estrutural:

[...] a privatização da natureza como resultado da crise difere absolutamente de outras emanações das crises do capital, como por exemplo, da crise das indústrias automotivas, da crise do setor financeiro ou até da crise da indústria do petróleo, pelo simples fato de a natureza, no seu sentido universal, ser uma dimensão elementar da reprodução da vida (a exemplo da terra, água e alimentos), característica que os setores supracitados da economia não são (MITIDIERO JUNIOR, 2016, p.20).

A apropriação da água de forma privada e mercadológica, assim como de outros recursos, pode ser em curto prazo uma garantia de lucro do poder econômico. Apesar de não ser uma novidade na história da humanidade o processo de mercadorização da água, nas últimas décadas, vem tomando força sem precedentes na história da humanidade. Criando uma ideia de raridade a água será totalmente presa, ignorando o seu aspecto universal e coletivo, e será completamente fatiada por empresas multinacionais que cobrarão pela sua utilização (MITIDIERO JUNIOR, 2016).

É nesse contexto que Harvey (2014) apresenta a ideia de acumulação por espoliação, tendo em vista que a mobilidade do capital cria e recria situações e ajustes espaciais para a 
reprodução ampliada. Por seu caráter estratégico na organização territorial e no processo de desenvolvimento econômico a disputa pelo controle dos recursos hídricos vai expandindo as fronteiras e incorporando novos territórios. O poder que envolve a água, seja em suas diferentes concepções, cultural, político ou econômico, deve ser pensado enquanto território com todas as suas implicações.

\section{Considerações finais}

Durante os nove séculos de convivência no território do Cariri os índios Kariris mantiveram uma relação com a água considerando-a como um elemento sagrado essencial para existência material e imaterial. Mas a partir da chegada dos colonizadores novos arranjos espaciais foram desencadeados e a lógica mercadológica da água foi colocada em prática. Essa apropriação privada ocorreu simultaneamente com violência física e simbólica aos índios Kariris e seus descendentes que ainda hoje resistem afirmando seu modo de vida na encosta da Chapada do Araripe.

Embora na passagem do turbulento século XX tenha ocorrido a execução das políticas de gestão de recursos hídricos e das legislações ambientais as formas de exploração da água foram avançando na medida em que a classe dominante passou ao controle e domínio dos territórios abundantes em água.

Com as políticas neoliberais a classe dominante forjou um discurso de escassez hídrica sem fundamentação teórica anulando o conteúdo político da discussão. Nesse cenário pensar a água de forma sistêmica foi um desafio praticamente inalcançável, quando, simultaneamente, pouco se avançou no sentido de preservar os corpos hídricos naturais, melhorar a qualidade da água através do seu reuso, melhorar a eficiência e implantar um uso racional.

A sabedoria das comunidades tradicionais herdeiras do conhecimento indígena mostra que outros caminhos são possíveis. São escolhas políticas que poderiam ser priorizadas, algumas delas, inclusive, já vêm sendo realizadas de forma exitosa pela sociedade civil e movimentos sociais como a utilização das chamadas tecnologias sociais hídricas, que propõe um olhar ecológico sobre a água, apresentando uma lógica oposta àquela difundida pelo capitalismo, nesse caso as tecnologias sociais hídricas transformam escassez em abundância ${ }^{12}$.

São essas ações que a ASA (Articulação do Semiárido) vem executando ao apresentar um novo paradigma de gestão hídrica na região semiárida do Nordeste brasileiro através de

\footnotetext{
${ }^{12}$ Entre as inúmeras tecnologias sociais hídricas destaca-se a cisterna de placa, barragem subterrânea, tanque de pedra, etc. 
estratégias alternativas de uso, conservação e captação de água. A ASA desenvolve ações simples como o aproveitamento da água de chuva, recurso praticado, por exemplo, pelos Kariris e que ainda hoje tem funcionado com sucesso.

Essa pesquisa, ainda que apresente resultados parciais, demonstra que transformar a água em mercadoria regulada segundo as leis do mercado se mostra como um fracasso. $\mathrm{Ou}$ seja, estabelecer um valor monetário a água se mostra quase impossível pela importância que ela oferece aos serviços ecológicos do planeta. O caso do Cariri cearense é, portanto, emblemático, pois o seu dinamismo econômico já reflete em diversos problemas ambientais. A demanda por água na região vem crescendo nos últimos anos e como o abastecimento é feito principalmente com água subterrânea os aquíferos vêm apresentando sinais de deficiência em sua recarga. Além disso, outros problemas como desmatamento, poluição e ocupação irregular da encosta da Chapada do Araripe se intensificaram nos últimos anos podendo se acentuar com a chegada de grandes projetos como o CAC.

Constatamos, portanto, que os problemas da mercadorização da água além de não resolverem a questão da escassez não conseguem deter a agressão ambiental. A natureza política dessa encruzilhada econômica apresenta como solução mais mercado, mas técnica e mais controle e domínio sobre os recursos hídricos. O avanço das formas de uso exploratório gera mais degradação dos corpos hídricos, contraditoriamente, as necessidades econômicas do período neoliberal exige um crescente aumento da demanda hídrica.

\section{Referências}

ARAÚJO, A. G. A cidade de Frei Carlos. Crato: Faculdade de Filosofia do Crato. Coleção estudos e pesquisas, vol. 5, 1971.

BRITO, A. C. R. Águas para que(m): grandes obras hídricas e conflitos territoriais no Ceará. Curitiba: Editora CRV, 2016.

CARIRI, Rosemberg. A pedra da Batateira. Disponível em: <http://agoracariri. blogspot.com.br/2008/04/ritos-lendas-e-mitos-do-cariri-2-a pedra da batateira>. Acesso em: 21 mai. 2016.

CEARÁ, Assembleia Legislativa do Estado. Cenário atual dos recursos hídricos do Ceará. Fortaleza: INESP, 2008.

DNPM, Projeto Avaliação Hidrogeológica da Bacia Sedimentar do Araripe. Ministério de Minas e Energia, Recife: DNPM, 1996.

EIA/RIMA. Estudo de Impacto Ambiental - EIA, Relatório de Impacto Ambiental RIMA. Estudo de viabilidade técnico - econômica, estudo ambiental e ante-projeto do trecho Jatí - Cariús do Cinturão de Águas do Ceará - CAC, Secretaria de Recursos Hídricos (SRH), 2010.

FIGUEIREDO FILHO, José de. História do Cariri. Vol. I. Coedição Secult/Edições URCA. Fortaleza: Edições UFC, 2010. 
HARVEY, D. O novo imperialismo. $8^{\circ}$ ed. São Paulo: Edições Loyola, 2014.

LIMAVERDE, R. Diagnóstico Arqueológico na Área do Cinturão das Águas do Ceará (CAC) - Etapa 1 - Trecho Jati/Cariús. Relatório de Campo, 2013.

MENEZES, Edith Oliveira de. O Cariri cearense. In. SILVA, J. B.; CAVALCANTE, T. C.; DANTAS, E. W. C. (Orgs.). Ceará: um novo olhar geográfico. $2^{\circ}$ ed. Fortaleza: Edições Demócrito Rocha, 2007.

MITIDIERO JUNIOR, M. A. Crise do capital global, natureza e agronegócio. In. (Org.) FILHO, E. da S.R. et al. Questão Agrária e conflitos territoriais. São Paulo: Outras Expressões, 2016.

NOBRE, F.W. Os efeitos do Cinturão das Águas do Ceará - CAC no distrito de Baixio das Palmeiras - Crato-CE. 2016. Dissertação. Mestrado em Desenvolvimento Regional Sustentável - PRODER, Universidade Federal do Cariri - UFCA, Juazeiro do Norte, 2017.

PINHEIRO, Irineu. O Cariri. Coedição Secult/Edições URCA. Fortaleza: edições UFC, 2010.

POMPEU SOBRINHO, Th. As origens dos índios Cariris. Revista do Instituto do Ceará. Tomo LXIV, p.314-347. Fortaleza: Editora Instituto do Ceará, 1950.

SABOIA, Andrey Luna. Água para quem? Os meandros da gestão de recursos hídricos no estado do Ceará. 2015. Dissertação (Programa de Pós-Graduação em Desenvolvimento e Meio Ambiente) - Universidade Federal do Ceará, Fortaleza, 2015.

STUDART, C. As tríbus indígenas do Ceará. In. GIRÃO, R.; FILHO, A.M. O Ceará. Fortaleza: Fundação Waldemar Alcântara, 2011.

UNESCO, Relatório Mundial das Nações Unidas Sobre o Desenvolvimento dos Recursos Hídricos. Relatório - WWDR4, 2012. 